\title{
Photooxidation of Toluene: Correlation of Noble Metal Loading on Titania and Activation Energy
}

\author{
Haroon ur Rashid, ${ }^{1}$ Mohammad Sadiq, ${ }^{2}$ Muhammad Abid Zia, ${ }^{3}$ Saima Sadiq, \\ M. Sohail Ahmad, ${ }^{2}$ Razia Aman, ${ }^{2}$ Muhammad Humayun, ${ }^{4}$ and Rahmat $\mathrm{Ali}^{5}$ \\ ${ }^{1}$ Department of Chemistry, Sarhad University of Science and Information Technology, Peshawar, Pakistan \\ ${ }^{2}$ Department of Chemistry, University of Malakand, Chakdara, Dir (L), Khyber Pakhtunkhwa, Pakistan \\ ${ }^{3}$ Department of Chemistry, University of Education, Attock Campus, Attock, Pakistan \\ ${ }^{4}$ University of Engineering and Technology, Peshawar, Pakistan \\ ${ }^{5}$ National Center of Excellence in Physical Chemistry, University of Peshawar, Peshawar, Pakistan
}

Correspondence should be addressed to Mohammad Sadiq; sadiq@uom.edu.pk

Received 1 September 2016; Accepted 27 October 2016

Academic Editor: Zhaoyang Lin

Copyright (C) 2016 Haroon ur Rashid et al. This is an open access article distributed under the Creative Commons Attribution License, which permits unrestricted use, distribution, and reproduction in any medium, provided the original work is properly cited.

A series of platinum and palladium supported on titania catalysts were prepared by wet impregnation method with the Pt or Pd loading varying in the range of 0.1-1.2 weight percent. The catalysts were characterized by SEM, EDX, XRF, XRD, FT-IR, and BET surface area analysis. The catalysts were tested for their efficiency in the liquid phase solvent-free photooxidation of toluene to benzyl alcohol and benzaldehyde in the presence of molecular oxygen. The effect of noble metal contents on the activation energy was studied. Activation energy was found to be in a reciprocal relation to the platinum or palladium content of the catalyst. The percent conversion of toluene was observed to increase in response to an increase in the metal loading on titania. The apparent quantum yield, however, was independent of the platinum or palladium content of the catalyst.

\section{Introduction}

Photocatalysis is based on the consumption of solar energy and has been extensively considered to be the approach of green chemistry. There are many applications of titanium dioxide such as scratch-resistant optical coating paint pigments, which can also show high activity to photooxidation reaction, in which the researchers are beginning to exploit the field [1]. $\mathrm{TiO}_{2}$ is a well-known and most applicable photocatalyst; it provides a best agreement between aqueous media and catalytic activity. It has been broadly studied due to its outstanding properties such as thermal stability, nontoxicity, low cost, availability, chemical inertness, and oxidizing ability of organic compounds [2-5]. Below $390 \mathrm{~nm}$, titania can be activated by UV radiations. Absorption of light results in charge production and consequently activity is increased. Photocatalytic reactions of $\mathrm{TiO}_{2}$ have attracted much attention of the researchers in the field of organic synthesis [6-8]. The photocatalytic activity of titania depends on its crystalline phase. $\mathrm{TiO}_{2}$ (anatase) was thoroughly investigated as a photocatalyst for the oxidation of cyclohexane and cyclohexanol. The photocatalytic activity of titania can be enhanced by incorporating metal ions. A variety of methods such as precipitation, doping, and impregnation are used to introduce metal ions into titania [9-11].

Recently, the effects of noble metals such as platinum, gold, palladium, and rhodium on the photocatalytic activity of titania have been extensively studied [12-15]. It has been found that the addition of these noble metals substantially improves the photocatalytic activity of titania. This effect may be attributed to shutting and storing of photogenerated electrons from the titania to acceptor. Platinum loading especially effectuates a remarkable enhancement in the photocatalytic activity of titania through the formation of Schottky barrier at the $\mathrm{Pt}$ or $\mathrm{Pd} / \mathrm{TiO}_{2}$ interface [16]. However, many parameters can alter the enhancing effect of noble metal 
on the photocatalytic activity of titania such as surface conditions, particle size, noble metal loading, dispersion of active metal on the surface, and the method adopted for deposition of noble metals [17-20].

In this study, our aim was to explore the correlation of noble metals loading such as platinum and palladium on titania and activation energy, in the liquid phase photooxidation of toluene in solvent-free condition with molecular oxygen.

\section{Experimental}

2.1. General. All chemicals used in this study were of high purity grade and were used without further purification. Mercury arc lamp (TQ-150, $180 \mathrm{~W}$ ) was used as a light source, while glass filter was used to filter UV radiation. Actinometer (potassium oxalate-ferrioxalate) was used to determine lamp flux. Gases like nitrogen, oxygen, and hydrogen were supplied by BOC Pakistan and were further purified by specific filters (C.R.S.Inc.202268 and C.R.S.Inc.202223).

2.2. Preparation of the Catalyst. $\mathrm{TiO}_{2}$ was prepared from its precursor compound $\left(\mathrm{TiCl}_{4}\right)$ by treatment with ice cold diluted $\mathrm{H}_{2} \mathrm{SO}_{4}$ solution. The mixture was vigorously stirred for 30 minutes and then heated at $60^{\circ} \mathrm{C}$. The mixture was cooled to room temperature for ammonolysis. At $\mathrm{pH} 7$, white precipitate of titania was filtered out from the mixture, washed, dried, and then calcined at $400^{\circ} \mathrm{C}\left(1^{\circ} \mathrm{C} / \mathrm{min}\right)$ and retained the temperature for 6 hours.

Platinum or palladium supported on $\mathrm{TiO}_{2}$, with metal content ranging from 0.1 to $1.2 \mathrm{wt} \%$, was synthesized by incipient wetness technique. A paste of $\mathrm{TiO}_{2}$ was formed in the aqueous solution of $\mathrm{PtCl}_{4}$ or $\mathrm{PdCl}_{2}$ (containing calculated amount of $\mathrm{Pt} / \mathrm{Pd}$ ) and dried in oven at $105^{\circ} \mathrm{C}$ overnight. The sample was then subjected to calcination at $400^{\circ} \mathrm{C}\left(1^{\circ} \mathrm{C} / \mathrm{min}\right)$ and then maintained for 6 hours at the same temperature. The calcined catalyst was pulverized and finally reduced in a mixture of $\mathrm{H}_{2}$ and $\mathrm{N}_{2}$ gases at a flow rate of $40 \mathrm{~mL} / \mathrm{min}$ for 9 hours at $240^{\circ} \mathrm{C}$.

2.3. Characterization of the Catalyst. The platinum and palladium supported on $\mathrm{TiO}_{2}$ catalysts were characterized by modern technique such as scanning electron microscopy (SEM) of the sample and were recorded on SEM (JSM 5910, Jeol, Japan), energy dispersive X-ray spectroscopy (EDX) of the prepared catalyst was recorded on EDX detector (INC200, Oxford, UK), and X-ray fluorescence spectrometry was performed by XRF, Rigaku ZSX-100e. Metal dispersion was calculated on the basis of $\mathrm{CO}$ chemisorption, where $\mathrm{M} / \mathrm{CO}=1$. XRD was performed by X-ray diffractometer (Rigaku D/Max-II, Cu Tube, Japan), and surface area of the catalyst was determined by surface area and pore size analyzer (Quantachrome, Nova 2200). FT-IR spectra of the catalysts were recorded by Fourier Transform Infrared Spectrophotometer "IR Prestige, Shimadzu Japan."

2.4. Catalytic Test. Pyrex glass batch reactor was loaded with $20 \mathrm{~mL}$ toluene and $100 \mathrm{mg}$ catalyst. Nitrogen and oxygen

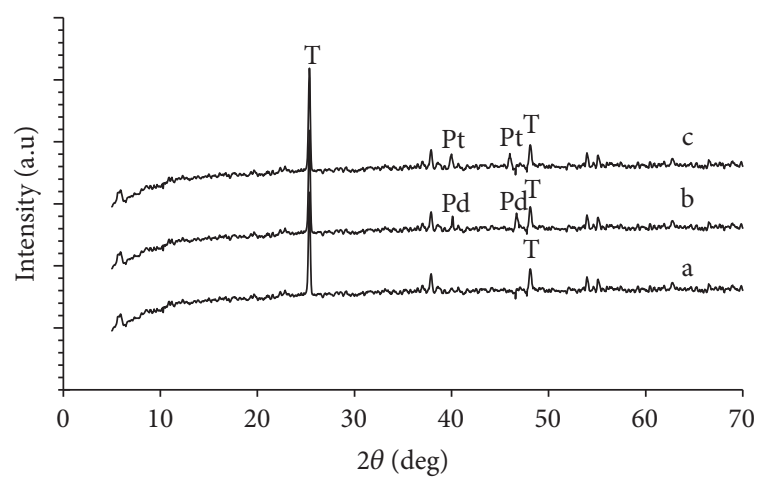

Figure 1: XRD pattern of (a) anatase $\mathrm{TiO}_{2}$, (b) $\mathrm{Pd} / \mathrm{TiO}_{2}$, and (c) $\mathrm{Pt} / \mathrm{TiO}_{2}$ ( $\mathrm{T}$ : anatase $\mathrm{TiO}_{2}$, Pt: platinum, and Pd: palladium).

were bubbled through the reaction mixture with their combined flow rate of $40 \mathrm{~mL} / \mathrm{min}$ while the reaction mixture was irradiated (lamp flux; $1.28 \times 10^{17} \mathrm{~h} \nu / \mathrm{s}$ ) at a specified temperature $(303,313,323$, and $333 \mathrm{~K})$ for a specified duration (1.5-3 hrs). On completion of the runs, each sample was filtered, treated with excess of water in order to remove the trace of benzoic acid, and analyzed by GC (PerkinElmer Clarus 580) equipped with FID and column (rtx@-Wax 30 m, $0.5 \mathrm{~mm} \mathrm{ID}$, and $0.5 \mathrm{~nm}$ ) for quantification of benzyl alcohol and benzaldehyde. Apparent quantum yield was calculated by using the standard method [21] with the following formula:

$$
\Phi_{a}=\left.\frac{\left(-d\left[C_{r}\right] / d t\right) V}{I_{i}}\right|_{t=0}
$$

where $\Phi_{a}$ is apparent quantum yield, $I_{i}$ (intensity of incidence irradiant $)=d[\mathrm{~h} \nu]_{\text {incidence }} / d t, C_{r}$ is concentration of reactants, and $V$ is volume of suspension.

\section{Results and Discussion}

3.1. Characterization of the Catalyst. XRD reflections obtained for titania and metal supported on titania are presented in Figure 1, which shows the characteristic anatase peaks at $2 \theta=25^{\circ}$ and $48^{\circ}$, and the observed pattern clarifies the absence of brookite and rutile phase of titania. No peaks for platinum or palladium were recorded at low Pt or Pd loading, while the presence of platinum peaks appeared at $2 \theta=40^{\circ}$ and $46^{\circ}$ as platinum loading exceeded $1 \mathrm{wt} \%$, while palladium is indicated by peaks appearing at $2 \theta=40.1^{\circ}$ and $46.7^{\circ}$ [22]. The SEM images of noble metals supported on $\mathrm{TiO}_{2}$ (ranging from 15 to $110 \mathrm{~nm}$ ) are presented in Figure 2, which show smooth morphology of the catalyst surface. The EDX spectrum of the $\mathrm{Pt}$ or $\mathrm{Pd} / \mathrm{TiO}_{2}$ is presented in Table 1 which clearly confirms the presence of $\mathrm{Pt}$ and $\mathrm{TiO}_{2}$ or $\mathrm{Pd}$ and $\mathrm{TiO}_{2}$ in its structure; there is no other element or chloride ion present on the surface of titania. BET surface area of $\mathrm{TiO}_{2}$ was $55.3 \mathrm{~m}^{2} / \mathrm{g}$ while platinized titania had a surface area of 41.7, 35.6, 31.9, 29, and $26 \mathrm{~m}^{2} / \mathrm{g}$ for $0.1 \mathrm{wt} \% \mathrm{Pt} / \mathrm{TiO}_{2}, 0.5 \mathrm{wt} \%$ $\mathrm{Pt} / \mathrm{TiO}_{2}, 0.7 \mathrm{wt} \% \mathrm{Pt} / \mathrm{TiO}_{2}, 1.0 \mathrm{wt} \% \mathrm{Pt} / \mathrm{TiO}_{2}$, and $1.2 \mathrm{wt} \%$ $\mathrm{Pt} / \mathrm{TiO}_{2}$, respectively, as shown in Table 2. The decreasing trend of surface area with Pt loading may be attributed to 


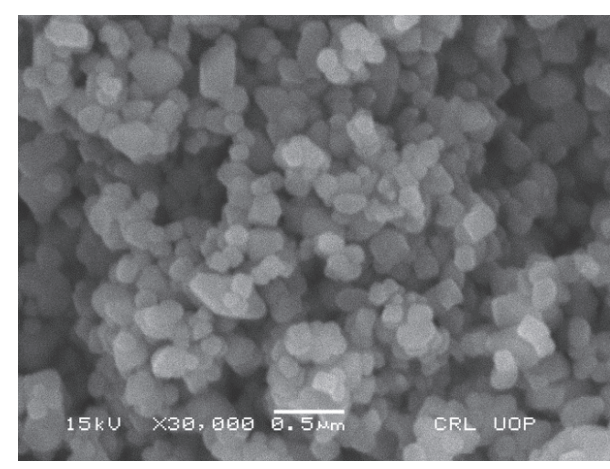

(a)

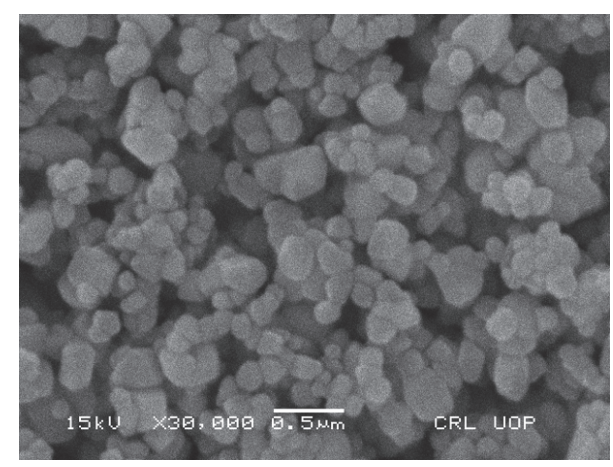

(b)

Figure 2: SEM images of (a) $0.1 \% \mathrm{Pt} / \mathrm{TiO}_{2}$ and (b) $0.1 \% \mathrm{Pd} / \mathrm{TiO}_{2}$ used as a photocatalyst for liquid phase oxidation of toluene.

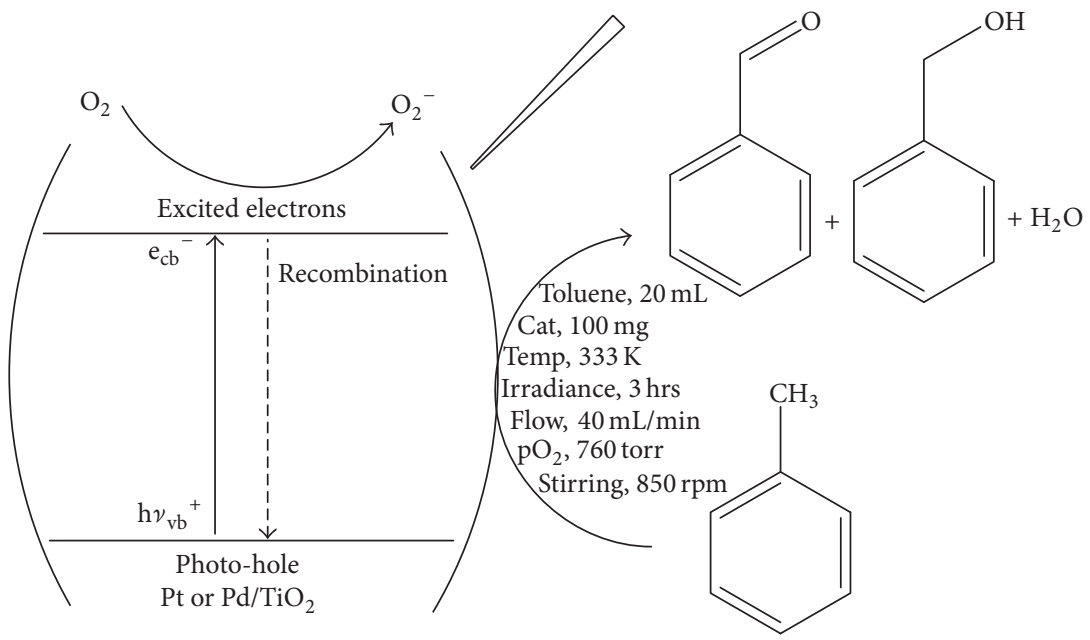

Scheme 1: $\mathrm{Pt} / \mathrm{TiO}_{2}$ or $\mathrm{Pd} / \mathrm{TiO}_{2}$ catalyzing photooxidation reaction of toluene.

the blockage of surface pore by platinum or perhaps high temperature treatment makes the catalyst aggregated and further reduces the surface area from 0.1 to $1.2 \mathrm{wt} \% \mathrm{Pt} / \mathrm{TiO}_{2}$. And the surface area remained almost constant, without showing any change in response to palladium loading in the range of $0.1 \mathrm{wt} \%$ to $1.2 \mathrm{wt} \%$. The XRF analysis confirmed that the Pt loading results on $\mathrm{TiO}_{2}$ were $0.102,0.51,0.73$, 1.0 , and $1.2 \mathrm{wt} \%$, while the results for Pd loading on $\mathrm{TiO}_{2}$ were $0.112,0.53,0.76,1.25$, and 1.32 , respectively. The results provided by XRF showed very close agreement with the expected results. From Table 2, it can be seen that the dispersion of platinum on the support decreases from $35.8 \%$ to $17.5 \%$ at high Pt loading which explains why characteristic peak for platinum appears in the XRD when Pt loading surpasses $1 \mathrm{wt} \%$. Therefore, optimum Pt loading is critical because well dispersion of platinum on $\mathrm{TiO}_{2}$ surface may improve the electron surface distribution, while very high and uncontrolled Pt loading favors $\mathrm{e}^{-} / \mathrm{h}^{+}$(electron/hole) recombination which is undesirable.

3.2. Catalytic Test. The catalysts efficiently catalyzed the liquid phase, solvent-free oxidation of toluene to benzyl
TABLE 1: EDX analysis of the catalysts used for photooxidation of toluene.

\begin{tabular}{lccc}
\hline Catalyst & Elements & Weight \% & Atomic \% \\
\hline \multirow{2}{*}{$\mathrm{TiO}_{2}$} & O K & 46.35 & 72.12 \\
& Ti K & 53.65 & 27.88 \\
& Total & 100 & \\
\hline \multirow{2}{*}{$\mathrm{Pt} / \mathrm{TiO}_{2}$} & O K & 47.82 & 73.35 \\
& Ti K & 51.97 & 26.63 \\
& Pt M & 0.21 & 0.03 \\
& Total & 100 & \\
\hline \multirow{2}{*}{$\mathrm{Pd} / \mathrm{TiO}_{2}$} & O K & 42.67 & 69.06 \\
& Ti K & 57.18 & 30.91 \\
& Pd K & 0.15 & 0.04 \\
& Total & 100 & \\
\hline
\end{tabular}

alcohol and benzaldehyde, under mild reaction conditions, and the mechanisms are presented in Scheme 1. On photon absorption surface electron of $\mathrm{TiO}_{2}$ get exited from valence band to conduction band, creating electron-hole pair. Doping 
TABLE 2: Surface characteristics of $\mathrm{Pt} / \mathrm{TiO}_{2}$ and $\mathrm{Pd} / \mathrm{TiO}_{2}$ used for the photocatalytic oxidation of toluene.

\begin{tabular}{|c|c|c|c|c|}
\hline \multirow{2}{*}{ Catalyst } & \multirow{2}{*}{$\begin{array}{l}\text { Surface area } \\
\qquad\left(\mathrm{m}^{2} \mathrm{~g}^{-1}\right)\end{array}$} & \multicolumn{2}{|c|}{ Pt or Pd loading (wt\%) } & \multirow{2}{*}{ Pt or Pd dispersion $(\%)^{*}$} \\
\hline & & Expected & Determined & \\
\hline $\mathrm{TiO}_{2}$ & 55.3 & - & - & - \\
\hline $0.1 \% \mathrm{Pt} / \mathrm{TiO}_{2}$ & 41.7 & 0.1 & 0.102 & 35.8 \\
\hline $0.1 \% \mathrm{Pd} / \mathrm{TiO}_{2}$ & 51.9 & 0.1 & 0.112 & 36.3 \\
\hline $0.5 \% \mathrm{Pt} / \mathrm{TiO}_{2}$ & 35.6 & 0.5 & 0.51 & 30.4 \\
\hline $0.5 \% \mathrm{Pd} / \mathrm{TiO}_{2}$ & 49.5 & 0.5 & 0.53 & 30.9 \\
\hline $0.7 \% \mathrm{Pt} / \mathrm{TiO}_{2}$ & 31.9 & 0.7 & 0.73 & 25.9 \\
\hline $0.7 \% \mathrm{Pd} / \mathrm{TiO}_{2}$ & 47.1 & 0.7 & 0.76 & 25.1 \\
\hline $1 \% \mathrm{Pt} / \mathrm{TiO}_{2}$ & 29.2 & 1 & 1.05 & 22.6 \\
\hline $1 \% \mathrm{Pd} / \mathrm{TiO}_{2}$ & 41.7 & 1 & 1.25 & 21.1 \\
\hline $1.2 \% \mathrm{Pt} / \mathrm{TiO}_{2}$ & 26.4 & 1.2 & 1.21 & 17.5 \\
\hline $1.2 \% \mathrm{Pd} / \mathrm{TiO}_{2}$ & 39.3 & 1.2 & 1.32 & 18.2 \\
\hline
\end{tabular}

* Platinum or palladium dispersion was determined on the basis of chemisorption of platinum or palladium/CO=1.

of metals slows down the electron-hole recombination process and enhanced the photocatalytic activity of the catalyst. Sakthivel and coworkers [23] have reported that up to $1 \mathrm{wt} \%$ platinum loading increased the photocatalytic activity of titania while in this study the optimum platinum/palladium loading up to $1.2 \mathrm{wt} \%$ was observed. Electrons in the conduction band interact with oxygen while hole in the valance band interacts with toluene and precedes the reaction with free radical chain mechanism.

The platinum and palladium contents on the surface of $\mathrm{TiO}_{2}$ as a catalyst show enhancing effect on the $\%$ conversion of toluene to benzyl alcohol and benzaldehyde in the order $1.2 \mathrm{wt} \% \mathrm{Pt} / \mathrm{TiO}_{2}>1 \mathrm{wt} \% \mathrm{Pt} / \mathrm{TiO}_{2}>0.7 \mathrm{wt} \% \mathrm{Pt} / \mathrm{TiO}_{2}>$ 0.5 wt $\% \mathrm{Pt} / \mathrm{TiO}_{2}>0.1 \mathrm{wt} \% \mathrm{Pt} / \mathrm{TiO}_{2}>\mathrm{TiO}_{2}$; similar trend was also observed in $\mathrm{Pd} / \mathrm{TiO}_{2}$ catalyst. However, quantum yield is independent of $\mathrm{Pt}$ or $\mathrm{Pd}$ loading on $\mathrm{TiO}_{2}$ as given in Figures 3 and 4 . The metals on the surface of titania lead to an increase of the surface barrier and the space charge region becomes narrower, in turn increasing efficiency of the electron-hole separation as presented in Scheme 1:

$$
\begin{aligned}
& \frac{\mathrm{M}}{\mathrm{TiO}_{2}}+\mathrm{h} v \longrightarrow \mathrm{h}_{\mathrm{vb}}{ }^{+}+\mathrm{e}_{\mathrm{cb}}^{-} \\
& \mathrm{M}_{n}+\mathrm{e}_{\mathrm{cb}}^{-} \longrightarrow \mathrm{M}_{n}^{-} \\
& \mathrm{O}_{2}+\mathrm{M}_{n}^{-} \longrightarrow \mathrm{O}_{2}^{-\bullet}+\mathrm{M}_{n}
\end{aligned}
$$

where $\mathrm{M}=\mathrm{Pt}$ or $\mathrm{Pd}$ which suppressed the recombination process and enhanced the photocatalytic activity of $\mathrm{TiO}_{2}$ [24]. Furthermore, these metals on the surface of $\mathrm{TiO}_{2}$ reduce the existence of $\mathrm{OH}$ which reduces the photoreactivity [25]. Similarly, the \% conversion of toluene to benzyl alcohol and benzaldehyde is too low in dark reaction carried out with $1.2 \mathrm{wt} \% \mathrm{Pt} / \mathrm{TiO}_{2}$ or $1.2 \mathrm{wt} \% \mathrm{Pd} / \mathrm{TiO}_{2}$ in the same set of reaction conditions. The activation energy was calculated from the temperature study by Arrhenius equation $\ln k=\ln A-\left(E_{a} / R T\right)$ which shows decline as the $\mathrm{Pt}$ content of the catalyst increases as shown in Figure 5; $1.2 \mathrm{wt} \% \mathrm{Pt} / \mathrm{TiO}_{2}$ has the least activation energy, that is,
$47.6 \mathrm{kJmol}^{-1}$. This is much less than the activation energy of titania which is $60.3 \mathrm{kJmol}^{-1}$. In the case of $\mathrm{Pd} / \mathrm{TiO}_{2}$ catalyst the correlation activation energy and Pd loading were observed being the same as for $\mathrm{Pt} / \mathrm{TiO}_{2}$ catalyst. Therefore, all proceeding reactions were carried out at $1.2 \mathrm{wt} \% \mathrm{Pt}$ or $\mathrm{Pd} /$ $\mathrm{TiO}_{2}$. The comparative study of photo and dark oxidation of toluene with $1.2 \mathrm{wt} \% \mathrm{Pt}$ or $\mathrm{Pd}$ supported on $\mathrm{TiO}_{2}$ showed that the activation energy is too high for dark oxidation of toluene $\left(78.6 \mathrm{kJmol}^{-1}\right.$ and $80.5 \mathrm{kJmol}^{-1}$ ) compared to the photooxidation of toluene $\left(47.6 \mathrm{kJmol}^{-1}\right.$ and $\left.48.9 \mathrm{kJmol}^{-1}\right)$, respectively. The $\%$ conversion increase as the partial pressure of oxygen was varied in the range of $0-760$ Torr till the maximum $4.55 \mathrm{~mol} \%$ conversion. It was noted that there was no conversion under a flow of nitrogen alone while under a simultaneous flow of oxygen and nitrogen the conversion of toluene to benzyl alcohol and benzaldehyde was observed. The presence of oxygen as an oxidant is thus necessary for oxidation of toluene.

The quantum yield is the highest at intermediate loading ( $0.5 \%$ for Pt and $0.7 \%$ for Pd), while the conversion efficiency linearly increases with increase of $\mathrm{Pt} / \mathrm{Pd}$ loading which may be attributed to catalytic activity of noble metals.

3.3. Blank Test. The reaction was carried out with same reaction conditions, under the standard experimental setup without catalyst loading. The reaction was analyzed for the products (benzyl alcohol and benzaldehyde) but no trace of product was found; therefore, the reaction is photocatalytic oxidation.

3.4. Reusability of the Catalyst. The catalysts were used for six consecutive runs after washing, drying, and treatment at $453 \mathrm{~K}$ in inert atmosphere in $\mathrm{U}$ shape reactor. The FT-IR spectra of fresh, used, and washed catalysts $\left(\mathrm{Pt} / \mathrm{TiO}_{2}\right.$ and $\mathrm{Pd} / \mathrm{TiO}_{2}$ ) were presented in Figures 6 and 7, which revealed that only used catalysts have peaks for $\left(\mathrm{C}=\mathrm{O}, 1700 \mathrm{~cm}^{-1}\right)$ and broad peak $\left(-\mathrm{OH}, 3000-3300 \mathrm{~cm}^{-1}\right)$ while washed catalysts 


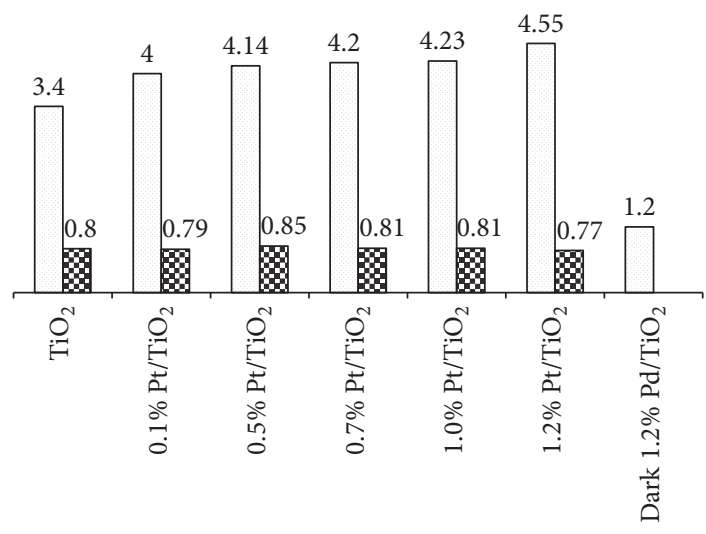

Catalyst

Mole\% conversion

图 Apparent quantum yield

Figure 3: Effect of Pt loading on titania used for solvent-free photo/dark oxidation of toluene. Reaction conditions: toluene: $20 \mathrm{~mL}$, cat: $100 \mathrm{mg}$, temp: $333 \mathrm{~K}$, irradiance: $3 \mathrm{hrs}$, flow: $40 \mathrm{~mL} / \mathrm{min}$, $\mathrm{pO}_{2}$ : 760 torr, and stirring: $850 \mathrm{rpm}$.

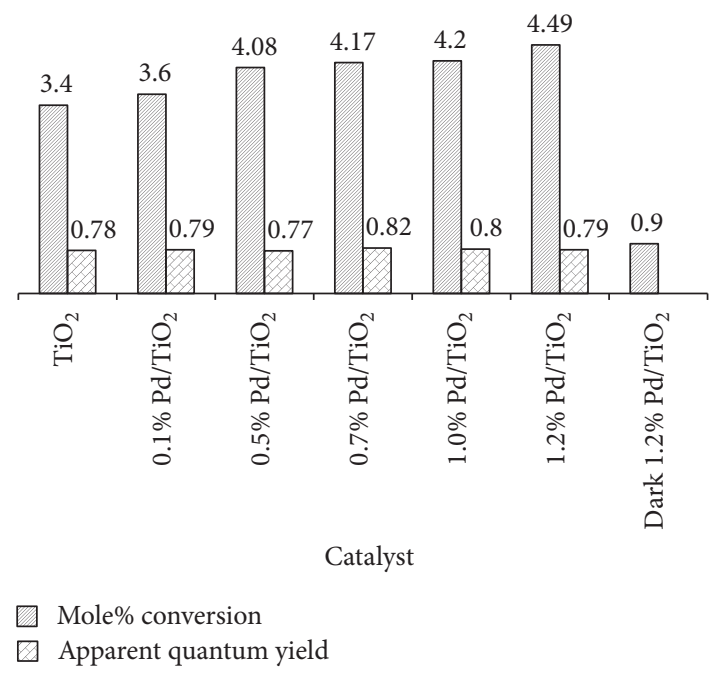

FIGURE 4: Effect of Pd loading on titania used for solventfree photo/dark oxidation of toluene. Reaction conditions: toluene: $20 \mathrm{~mL}$, cat: $100 \mathrm{mg}$, temp: $333 \mathrm{~K}$, irradiance: $3 \mathrm{hrs}$, flow: $40 \mathrm{~mL} / \mathrm{min}$, $\mathrm{pO}_{2} ; 760$ torr, and stirring: $850 \mathrm{rpm}$.

have no peaks for coke or residue. The catalysts are quite stable with retaining same catalytic activity for six experimental runs as shown in Figure 8.

\section{Conclusion}

Pt and Pd supported on titania as photocatalysts are capable of efficiently catalyzing the oxidation of toluene to benzyl alcohol and benzaldehyde in liquid phase solvent-free condition with molecular oxygen. The comparative study of dark and photoreaction reveals that the reaction is photodependent. The decrease in activation energy with noble metal loading clarified that up to $1.2 \mathrm{wt} \% \mathrm{Pt}$ or Pd loading

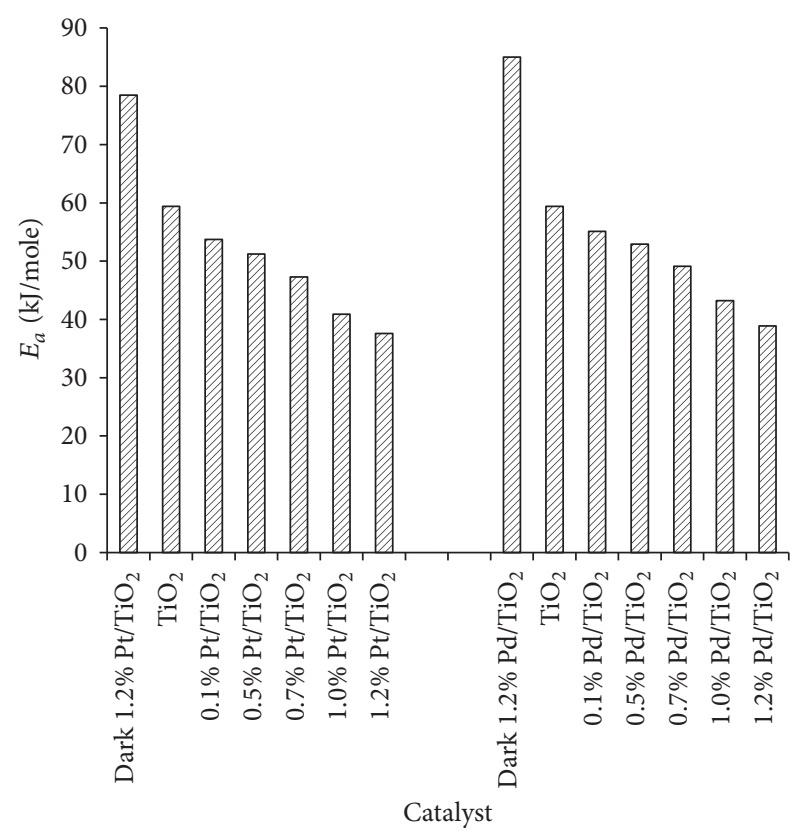

Figure 5: Plot for the correlation of activation energy and Pt or Pd content of photocatalyst. Reaction conditions: toluene: $20 \mathrm{~mL}$, temp: $303-333 \mathrm{~K}$, cat: $100 \mathrm{mg}$, irradiance: $3 \mathrm{hrs}$, flow: $40 \mathrm{~mL} / \mathrm{min}$, $\mathrm{pO}_{2}: 760$ torr, and stirring: $850 \mathrm{rpm}$.

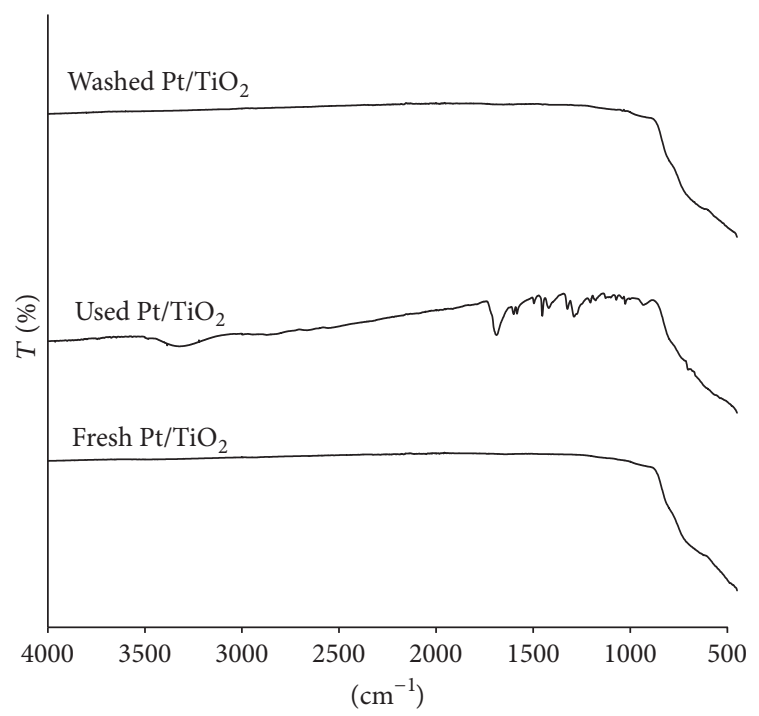

FIgure 6: FT-IR spectra of fresh $\mathrm{Pt} / \mathrm{TiO}_{2}$, used $\mathrm{Pt} / \mathrm{TiO}_{2}$, and washed $\mathrm{Pt} / \mathrm{TiO}_{2}$.

improved the photocatalytic activity of the catalyst by retarding the electron-hole recombination process. Furthermore, the activation energy shows reciprocal relation to platinum or palladium loading on titania.

\section{Competing Interests}

The authors declare no conflict of interests. 


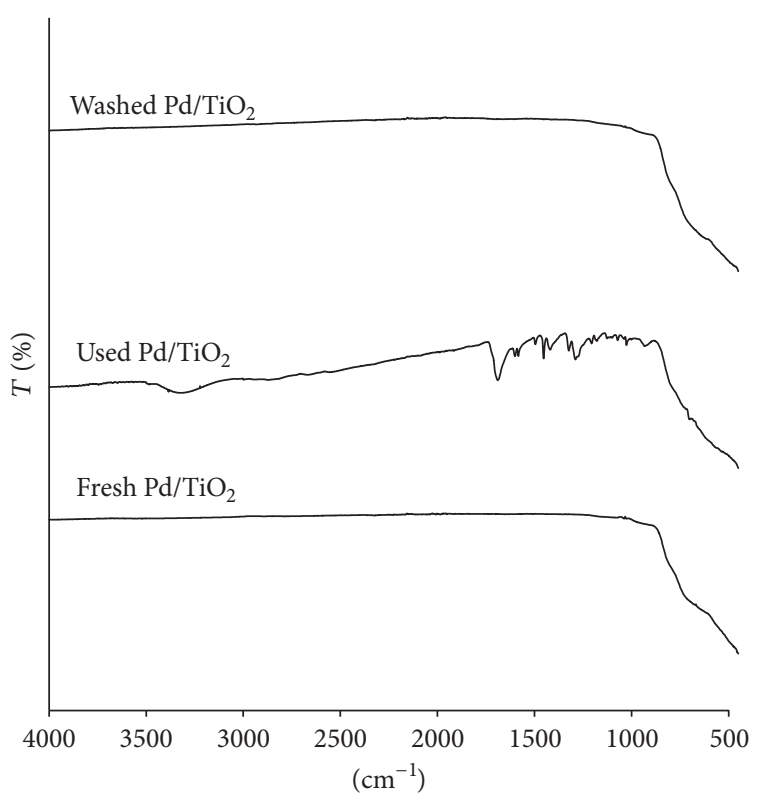

FIgure 7: FT-IR spectra of fresh $\mathrm{Pd} / \mathrm{TiO}_{2}$, used $\mathrm{Pd} / \mathrm{TiO}_{2}$, and washed $\mathrm{Pd} / \mathrm{TiO}_{2}$.

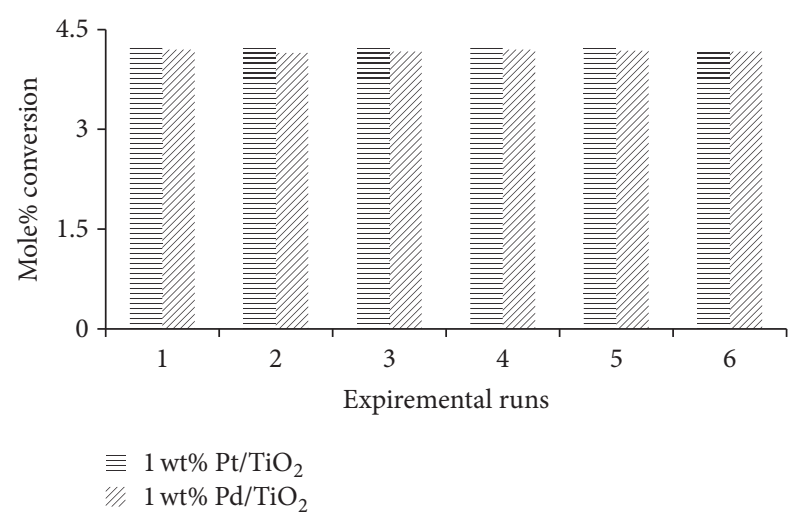

FIGURE 8: Life span of the catalysts for photooxidation of toluene. Reaction conditions: toluene: $20 \mathrm{~mL}$, cat: $100 \mathrm{mg}$, temp: $333 \mathrm{~K}$, irradiance: $3 \mathrm{hrs}$, flow: $40 \mathrm{~mL} / \mathrm{min}, \mathrm{pO}_{2}$ : 760 torr, and stirring: $850 \mathrm{rpm}$.

\section{Acknowledgments}

The authors greatly acknowledge the financial support from Higher Education Commission of Pakistan, Pakistan Science Foundation, and University of Malakand.

\section{References}

[1] A. Fujishima and T. N. Rao, "Recent advances in heterogeneous $\mathrm{TiO}_{2}$ photocatalysis," Proceedings of the Indian Academy of Sciences: Chemical Sciences, vol. 109, no. 6, pp. 471-486, 1997.

[2] A. E. Eliyas, L. Ljutzkanov, I. D. Stambolova et al., "Visible light photocatalytic activity of $\mathrm{TiO}_{2}$ deposited on activated carbon," Central European Journal of Chemistry, vol. 11, no. 3, pp. 464470, 2013.

[3] K. Wantala, S. Neramittagapong, A. Neramittagapong, K. Kasipar, S. Khaownetr, and S. Chuichulcherm, "Photocatalytic degradation of alachlor on $\mathrm{Fe}^{-\mathrm{TiO}_{2}}$-immobilized on GAC under black light irradiation using Box-Behnken design," Materials Science Forum, vol. 734, pp. 306-316, 2013.

[4] T. D. Bui, A. Kimura, S. Ikeda, and M. Matsumura, "Determination of oxygen sources for oxidation of benzene on $\mathrm{TiO}_{2}$ photocatalysts in aqueous solutions containing molecular oxygen," Journal of the American Chemical Society, vol. 132, no. 24, pp. 8453-8458, 2010.

[5] H. I. De Lasa, B. Serrano, and M. Salaices, Photo Catalytic Reaction Engineering, Springer, New York, NY, USA, 2005.

[6] H. Khojasteh, M. Salavati-Niasari, A. Abbasi, F. Azizi, and M. Enhessari, "Synthesis, characterization and photocatalytic activity of $\mathrm{PdO} / \mathrm{TiO}_{2}$ and $\mathrm{Pd} / \mathrm{TiO}_{2}$ nano composites," Journal of Materials Science: Materials in Electronics, vol. 27, no. 2, pp. 1261-1269, 2016.

[7] G. Palmisano, V. Augugliaro, M. Pagliaro, and L. Palmisano, "Photocatalysis: a promising route for 21st century organic chemistry," Chemical Communications, no. 33, pp. 3425-3437, 2007.

[8] Y. Shiraishi and T. Hirai, "Selective organic transformations on titanium oxide-based photocatalysts," Journal of Photochemistry and Photobiology C: Photochemistry Reviews, vol. 9, no. 4, pp. 157-170, 2008.

[9] M. Ni, M. K. H. Leung, D. Y. C. Leung, and K. Sumathy, "A review and recent developments in photocatalytic watersplitting using $\mathrm{TiO}_{2}$ for hydrogen production," Renewable and Sustainable Energy Reviews, vol. 11, no. 3, pp. 401-425, 2007.

[10] F.-C. Wang, C.-H. Liu, C.-W. Liu, J.-H. Chao, and C.-H. Lin, "Effect of pt loading order on photocatalytic activity of $\mathrm{Pt} / \mathrm{TiO}_{2}$ nanofiber in generation of $\mathrm{H}_{2}$ from neat ethanol," Journal of Physical Chemistry C, vol. 113, no. 31, pp. 13832-13840, 2009.

[11] K. A. Connelly and H. Idriss, "The photoreaction of $\mathrm{TiO}_{2}$ and $\mathrm{Au} / \mathrm{TiO}_{2}$ single crystal and powder surfaces with organic adsorbates. Emphasis on hydrogen production from renewables," Green Chemistry, vol. 14, no. 2, pp. 260-280, 2012.

[12] R. Su, R. Tiruvalam, Q. He et al., "Promotion of phenol photodecomposition over $\mathrm{TiO}_{2}$ using $\mathrm{Au}, \mathrm{Pd}$, and $\mathrm{Au}-\mathrm{Pd}$ nanoparticles," ACS Nano, vol. 6, no. 7, pp. 6284-6292, 2012.

[13] H. Bahruji, M. Bowker, P. R. Davies, and F. Pedrono, "New insights into the mechanism of photocatalytic reforming on $\mathrm{Pd} / \mathrm{TiO}_{2}$," Applied Catalysis B: Environmental, vol. 107, no. 1-2, pp. 205-209, 2011.

[14] K. Mogyorósi, Á. Kmetykó, N. Czirbus, G. Veréb, P. Sipos, and A. Dombi, "Comparison of the substrate dependent performance of Pt-, Au- and Ag-doped $\mathrm{TiO}_{2}$ photocatalysts in $\mathrm{H}_{2}$ production and in decomposition of various organics," Reaction Kinetics and Catalysis Letters, vol. 98, no. 2, pp. 215-225, 2009.

[15] T. A. Egerton and J. A. Mattinson, "The influence of platinum on UV and 'visible' photocatalysis by rutile and Degussa P25," Journal of Photochemistry and Photobiology A: Chemistry, vol. 194, no. 2-3, pp. 283-289, 2008.

[16] T. A. Kandiel, R. Dillert, and D. W. Bahnemann, "Enhanced photocatalytic production of molecular hydrogen on $\mathrm{TiO}_{2}$ modified with Pt-polypyrrole nanocomposites," Photochemical and Photobiological Sciences, vol. 8, no. 5, pp. 683-690, 2009.

[17] C. A. Emilio, R. Gettar, and M. I. Litter, "Mechanism of degradation of nitrilotriacetic acid by heterogeneous photocatalysis over $\mathrm{TiO}_{2}$ and platinized $\mathrm{TiO}_{2}$," Journal of Applied Electrochemistry, vol. 35, no. 7-8, pp. 733-740, 2005.

[18] B. Abida, L. Chirchi, S. Baranton et al., "Preparation and characterization of $\mathrm{Pt} / \mathrm{TiO}_{2}$ nanotubes catalyst for methanol 
electro-oxidation," Applied Catalysis B: Environmental, vol. 106, no. 3-4, pp. 609-615, 2011.

[19] U. Siemon, D. Bahnemann, J. J. Testa, D. Rodríguez, M. I. Litter, and N. Bruno, "Heterogeneous photocatalytic reactions comparing $\mathrm{TiO}_{2}$ and $\mathrm{Pt} / \mathrm{TiO}_{2}$," Journal of Photochemistry and Photobiology A: Chemistry, vol. 148, no. 1-3, pp. 247-255, 2002.

[20] C. Belver, M. J. López-Muñoz, J. M. Coronado, and J. Soria, "Palladium enhanced resistance to deactivation of titanium dioxide during the photocatalytic oxidation of toluene vapors," Applied Catalysis B: Environmental, vol. 46, no. 3, pp. 497-509, 2003.

[21] Y.-B. Xie and C.-W. Yuan, "Calculation method of quantum efficiency to $\mathrm{TIO}_{2}$ nanocrystal photocatalysis reaction," Journal of Environmental Sciences, vol. 14, no. 1, pp. 70-75, 2002.

[22] K. H. Leong, H. Y. Chu, S. Ibrahim, and P. Saravanan, "Palladium nanoparticles anchored to anatase $\mathrm{TiO}_{2}$ for enhanced surface plasmon resonance-stimulated, visible-light-driven photocatalytic activity," Beilstein Journal of Nanotechnology, vol. 6, no. 1, pp. 428-437, 2015.

[23] S. Sakthivel, M. V. Shankar, M. Palanichamy, B. Arabindoo, D. W. Bahnemann, and V. Murugesan, "Enhancement of photocatalytic activity by metal deposition: characterisation and photonic efficiency of $\mathrm{Pt}, \mathrm{Au}$ and $\mathrm{Pd}$ deposited on $\mathrm{TiO}_{2}$ catalyst," Water Research, vol. 38, no. 13, pp. 3001-3008, 2004.

[24] L. M. Ahmed, I. Ivanova, F. H. Hussein, and D. W. Bahnemann, "Role of platinum deposited on $\mathrm{TiO}_{2}$ in photocatalytic methanol oxidation and dehydrogenation reactions," International Journal of Photoenergy, vol. 2014, Article ID 503516, 9 pages, 2014.

[25] W. Choi, A. Termin, and M. R. Hoffmann, "The role of metal ion dopants in quantum-sized $\mathrm{TiO}_{2}$ : correlation between photoreactivity and charge carrier recombination dynamics," The Journal of Physical Chemistry, vol. 98, no. 51, pp. 1366913679, 1994. 

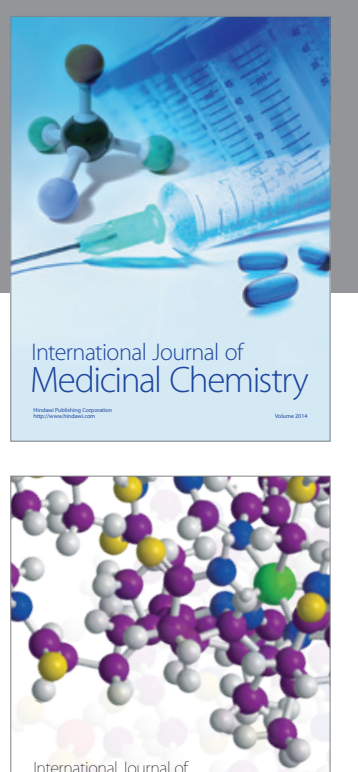

Carbohydrate Chemistry

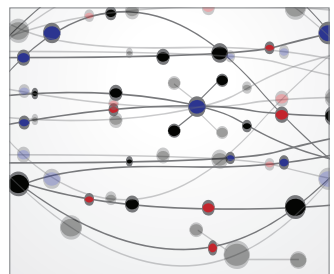

The Scientific World Journal
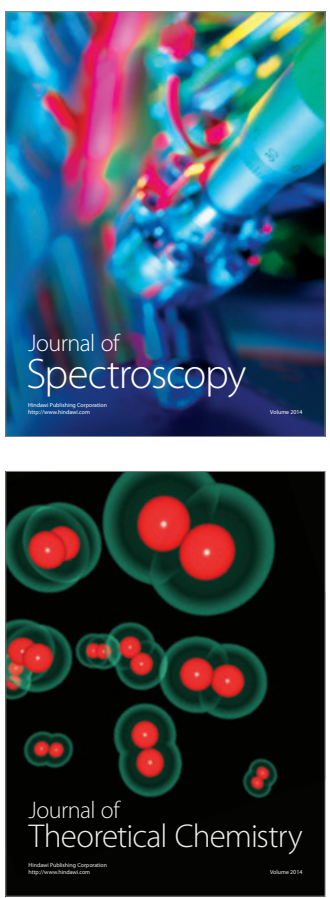
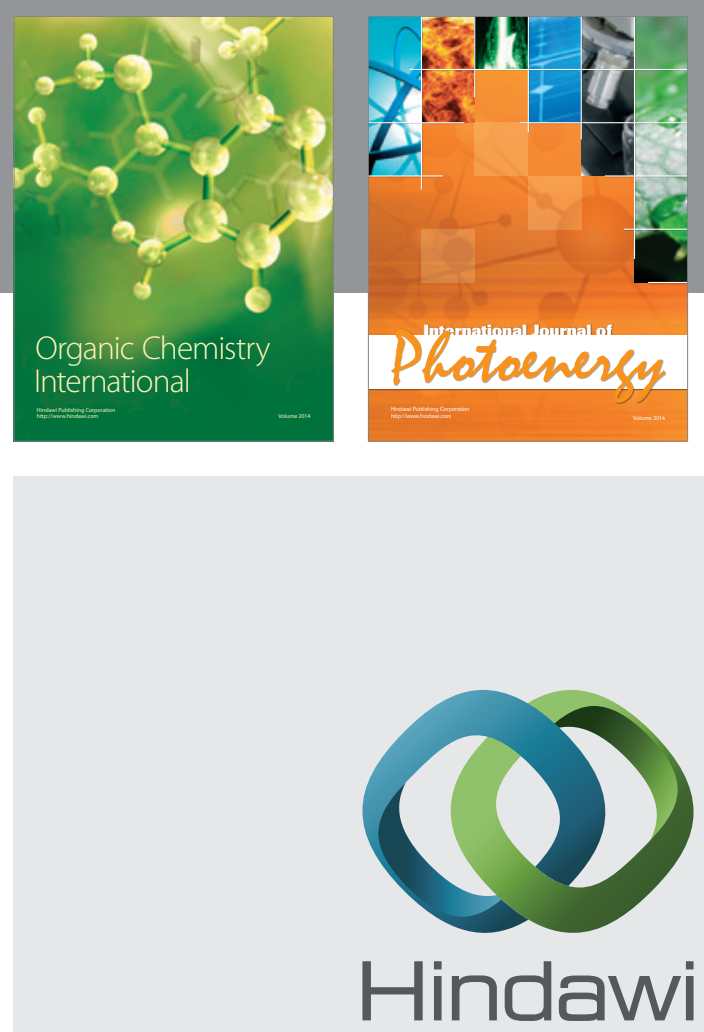

Submit your manuscripts at

http://www.hindawi.com

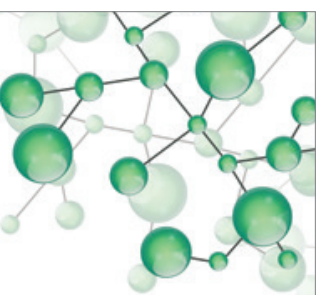

International Journal of

Inorganic Chemistry

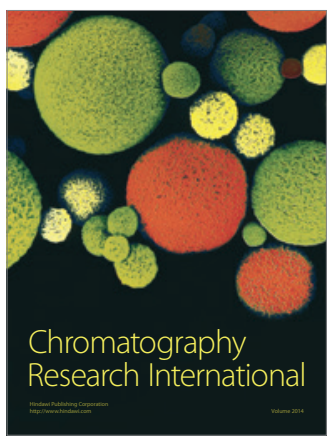

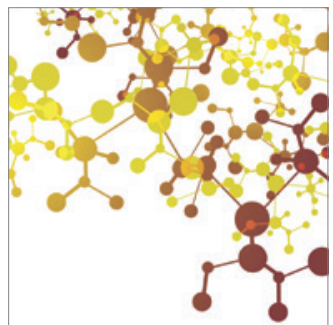

Applied Chemistry
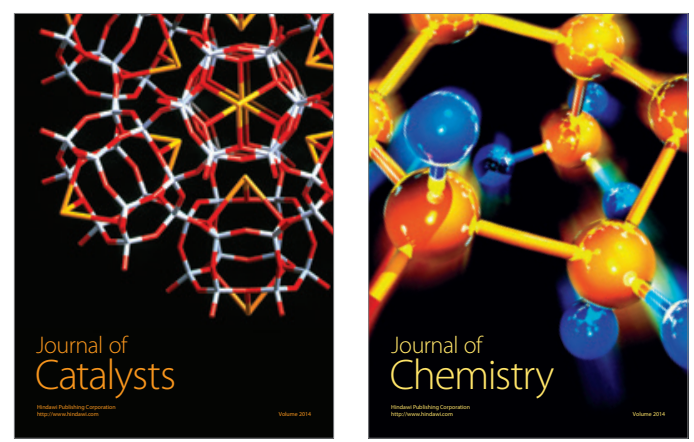
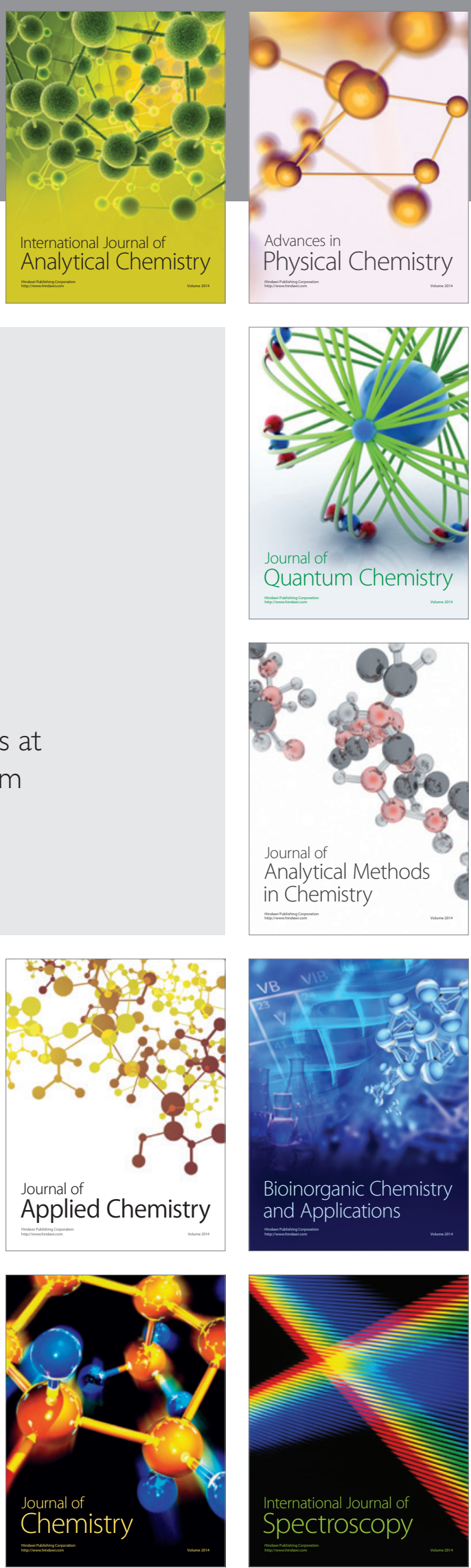